\title{
A Survey on Ambiguity within the Framework of TG Grammar in College English Teaching
}

\author{
Fangfang Ding \\ Sichuan Agricultural University, Ya'an, China
}

\begin{abstract}
Ambiguity is one of the common phenomenons of any human language, especially for Chinese students to master. Within the framework of TG grammar, the article tries to analyze the structural ambiguity, by comparison with the traditional grammar and structural approach. D- structure and S-structure and X-bar theory are introduced to explain the production and understanding of ambiguity.
\end{abstract}

Index Terms-structural ambiguity, TG grammar, D-structure and S-structure, X-bar theory, English teaching

\section{INTRODUCTION}

\section{A. An Overview on the Study of Ambiguity}

When ambiguity is talked, it can refer to words, pictures, or other media, which is to express more than one interpretation. Another term is vagueness in which specific and different interpretations exist. However, with information that is vague it is difficult to form any interpretation at the desired level of specificity. Context is an important factor in ambiguity. For instance, the same kind of information can be ambiguous in one context but not unambiguous in another.

Here are some examples cited from the internet (http://en.wikipedia.org/wiki/Syntactic_ambiguity):

The cow was found by a stream by a farmer. (Did the farmer find the cow near the stream? Or was the cow found near a stream that was near a farmer? Or did the stream find the cow near a farmer?)

John saw the man on the mountain with a telescope. (Who has the telescope? John, the man on the mountain, or the mountain?)

Flying planes can be dangerous. (Either the act of flying planes is dangerous, or planes that are flying are dangerous.)

They are hunting dogs. (Either "they" are hunting for dogs, or those dogs are a type known as "hunting dogs".)

Eye Drops Off Shelf. (Describing eye drops that came from a shelf, an eye that fell from its location on a shelf, or an eye that delivered a shelf)

I'm going to sleep. ("Going" can be a verb with destination "sleep" or an auxiliary indicating near future. So it can mean "I am (now) falling asleep", "I am (in the future) intending to sleep" or "I am leaving (this event) to (go and) sleep")

The word of the Lord came to Zechariah, son of Berekiah, son of Iddo, the prophet. (Which of the three is the prophet?)

The British left waffles on Falklands (Did the British leave waffles behind, or is there waffling by the British Left?)

Monty flies back to front. (Monty returns to the front line, Monty flies backwards, the Monty variety of flies are backwards, or the Monty variety of flies return to the front?)

The Electric Light Orchestra (An orchestra of electric lights, or a light orchestra that's electric)

Stolen painting found by tree. (Either a tree found a stolen painting, or a stolen painting was found sitting next to a tree.)

I'm glad I'm a man, and so is Lola. (can mean "Lola and I are both glad I'm a man", or "I'm glad Lola and I are both men", or "I'm glad I'm a man, and Lola is also a man", or "I'm glad I'm a man, and Lola is also glad to be a man"). Ray Davies deliberately wrote this ambiguity into the song, referring to a cross-dresser.

Rubber baby buggy bumpers. (Bumpers made of rubber designed for baby buggies, bumpers made for buggies that carry rubber babies, or bumpers for rubber buggies that carry babies.)

Little Hope Given Brain-Damaged Man (A brain-damaged man is unlikely to recover, or a brain-damaged man is causing another situation to have little hope of resolution, or someone gave a brain-damaged man to a small girl named Hope.)

Somali Tied to Militants Held on U.S. Ship for Months. (Either the Somali was held for months, or the Somali was just now linked to militants who were held for months. One could also imagine rope was involved, at which point lexical ambiguity comes into play.)

Free Ireland. (Is it a syntactical entity, a Republican call-to-arms or just an amazingly good deal?)

Ambiguity is an interesting topic and the study about ambiguity has a long history. Like many other issues, it could be traced back to ancient Greek period, when its study was within the scope of philosophy. Plato is regarded as the first 
philosopher who studies ambiguity. However, he looks at ambiguity as no more than the main cause of sophism and wrong deduction. Following his study, Aristotle makes a comparatively comprehensive study about this phenomenon. He discusses ambiguity in his work De Sophistics Elenchis, in which he lists the six sources of misunderstanding, namely, ambiguity, amphiboly, combination, and division of words, accent, and form of expression. (1958:257).

There have appeared a great number of linguistic schools-Traditional Grammar, Structuralism, Transformational Generative Grammar, Case Grammar, and Functional Grammar, etc. For example, it is pointed out that both word and sentence had not only one meaning. Pragmatics regarded ambiguity as any language item which had more than one kind of recognitional meaning. Kilby and Roca (1982) made a distinction between lexical ambiguity and structural ambiguity. The former is based on the single word which has two or more meaning. The later refers to the combination relationship among the words in a sentence. All these just discuss several kinds of ambiguity but have no general summary. It must lead to practical difficulty and confusion. E .g. "a pretty interesting book" can be both lexical ambiguity and structural ambiguity. The part of speech of "pretty" is ambiguous, adjective or adverb. And "pretty" can modify, "interesting" or modify "book" with "interesting" together. On the other hand, some other definitions of ambiguity have strong academic color. The definition given by grammar, ambiguity is any sentence is that according to generative which has more than one grammatical analysis." Herndon (1976) regarded ambiguity as such kind of sentences with similar surface structure but different deep structure.

\section{B. Types of Ambiguity}

Lexical and structural ambiguity is contained in the area. Lexical ambiguity is the more common type, which we can find in our everyday language, such as nouns like 'chip', 'pen' and 'suit', verbs like 'call', 'draw' and 'run', and adjectives like 'deep', 'dry' and 'hard'. Ambiguity can be tested by various ways. One is to give the two antonyms that are not related. For example, 'hard' has both 'soft' and 'easy' as opposites. The other one is the conjunction reduction test, such as in the sentence 'The tailor pressed one suit in his shop and one in the municipal court', the ambiguous word is 'suit', as this word refer to an article of clothing and 'one' means a legal action.

As a phrase or sentence has more than one underlying structure, structural ambiguity occurs, taking the phrases 'Tibetan history teacher', 'a student of high moral principles' and 'short men and women', and the sentences 'The girl hit the boy with a book' and 'Visiting relatives can be boring' for examples. Why these ambiguities are said to be structural? The answer is that these phrases can be represented in two different ways structurally, such as '[Tibetan history] teacher' and 'Tibetan [history teacher]'. It is true that such ambiguities' existence offers explanations for a level of underlying syntactic structure. Look at the other structurally ambiguous sentence, 'The chicken is ready to eat'. This sentence could describe either a hungry chicken or a broiled chicken. This essay treats on structural ambiguity for its generative mechanism.

\section{Ambiguity in English Learning}

As Winter (1977) pointed, within the English Language there are many problems that as native speakers we don't? I really think about but when learning the English language as a second language there are many common misunderstandings and problems that arise. These can be divided into lexical and structural problems. One of the most common lexical problems is that of ambiguity. This is evident in idiomatic speech, homographs and homonyms within the English language.

Winter (1977) proposed that structural ambiguity is another common cause of linguistic problems and misunderstanding. This is because a word can have exactly the same structure but a different function. An example of this is "Flying planes can be dangerous.??. This could mean that flying a plane is dangerous or planes that are flying are dangerous therefore the whole context has to be considered before making a judgement about the meaning of the sentence. ? Although people are sometimes said to be ambiguous in how they use language, ambiguity is, strictly speaking, a property of linguistic expressions? This therefore implies that the language we use is built up of separate words and the structural ambiguity is caused by the combination of words in a sentence.

This kind of structure is confusing to a native English speaker so as a second language learner the context of the sentence needs to be fully understood before they are likely to fully understand the meaning of the sentence.

In conclusion, there are many ambiguities and linguistic problems within the language that native speakers take for granted to understand. However as a second language learner it is even more challenging to understand these ambiguous forms which therefore lead to confusion hence the development of these common linguistic problems. (Winter, 1977)

\section{An Generative Approach to Ambiguity}

\section{A. Traditional Grammar}

The traditional approach is also known as traditional grammar. It has a long history. It came from the study of Greek. Since Latin has a close connection to Greek in structure, the study was applied to Latin, and then to other European languages which are similar to Latin in form. Traditional grammar studies sentences mainly in two ways: paradigm analysis and parsing. An example is given:

(1) The girl saw the sailor with a telescope. 
In traditional grammar, with a telescope can be considered to modify the sailor, saw or the girl respectively and play the attributive, adverbial, and attributive functions respectively. So the production of ambiguity is the uncertainty of which part with a telescope modifies in a linear order. Thus it is interpretated in three ways.

a. The girl saw the sailor by using a telescope.

b. The girl saw the sailor taking a telescope.

c. The girl taking a telescope saw the sailor.

Seen from above, the traditional approach has several advantages. It briefly proves the presence of ambiguity and is greatly helpful for teachers to explain ambiguity. The method of ambiguity analysis is easy for understanding and application. It needs no extra study of other theories and language learners have not to know more beyond traditional grammar. However, it is obvious that before analysis of ambiguity, one must previously judge whether it is an ambiguity by intuitions and knowledge of traditional grammar, which is not dependable. What is more, the traditional grammar is based on Latin and it tries to impose the Latin categories and structures on other language, and regard the written language as primary. The third weakness of traditional grammar analysis is that it can not explain or prove the root reason for the generation of ambiguity.

\section{B. Structural Approach to Ambiguity}

The structural approach to the analysis of language was started by Saussure in the beginning of the 20th century. It developed into its climax in 1933 with the publishing of "language" by L.Bloomfield. The structural approach makes structural description of sentences to illustrate the parts of a sentence and the relationship among them.

Sentences are made up of phrases; phrases are made up of words which represents a hierarchical relation. Such a relation shows the inner layering of sentences. The hierarchical structure of a sentence can be revealed clearly by IC (immediate constituents) analysis. The same example can be dealt with by IC analysis.

a.

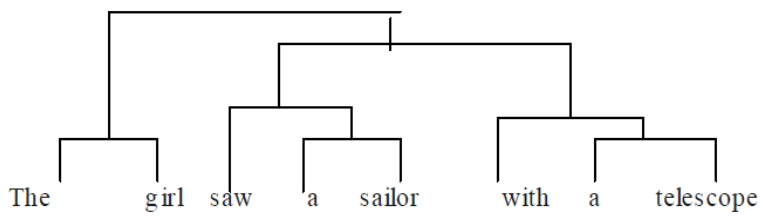

Here with a telescope is combined with saw a sailor so the sentence can be paraphrased as: with a telescope, the girl saw a sailor.

b.

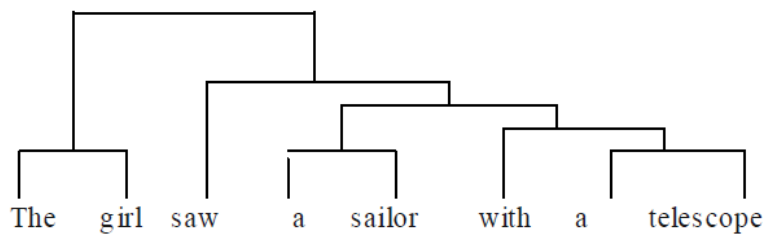

In this way, with a telescope is related to a sailor. Thus it can be understood as the sailor who took a telescope on him.

c.

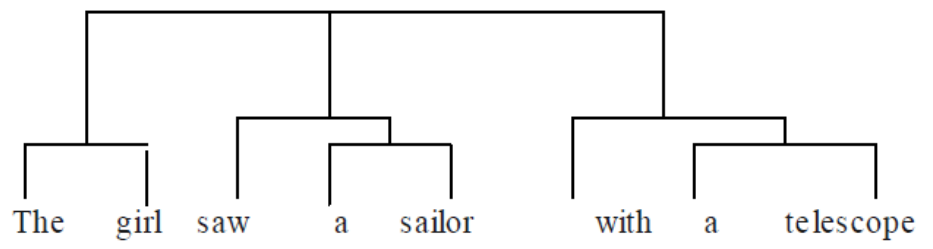

In the third case, with a telescope is connected with the girl and thus the whole sentence is interpretated as the girl with a telescope saw a sailor.

Concluded from the analysis above, IC analysis is more complicated than traditional grammar. It presents a clearer and more detailed description of the internal constituent hierarchical structure of a sentence. In the process of analysis, it is not only that the ambiguity is proved, but also the number of the ambiguities that a sentence can produce is indicated. If a sentence can be segmented in more than one way, ambiguity is suggested. IC analysis has disadvantages, at the same time, that it does not tell any information about the constituents that form the hierarchical structure. For example, if with a telescope is changed into on Saturday, the sentence has simply one meaning though the structure may still have three IC structures. 


\section{Transformational Generative Analysis of Ambiguity}

1. An introduction to transformational generative grammar

Transformational-Generative grammar (TG grammar) has been regarded as a revolution in linguistics in the mid 1950s. The publication of Noam Chomsky's Syntactic Structure in 1957 marked the beginning of Chomskyan revolution.

Proposed by Chomsky (1965), transformational-generative grammar sees language as a system of innate rules.' In Chomsky's view, a native speaker possesses a kind of linguistic competence. The child is born with knowledge of some linguistic universal. While acquiring his mother tongue, he compares his innate language system with that of his native language and modifies his grammar. Therefore, language learning is not a matter of habit formation, but an activity of building and testing hypothesis. As for the construct of a sentence, TG grammar describes it as composed of a deep structure, a surface structure and some transformational rules. From its birth to the present day, $\mathrm{T}$ G grammar has seen as four stages in its development. The first period is the period of logical structure of linguistic theory, from the fifties up to 1965. The aim of this period is to make linguistics a science. The second period of standard theory is from 1965to 1970.The topical question is that semantics should be studied in a linguistic theory. The third is the period of extended standard theory, from 1970 to 1980 . Now the discussion is focused on language universals and universal grammar. After that, it is GB period, as the theory now centers on problems in government and binding.

However, Chomsky's theory has been very controversial. Assuming a more objective tone, John Lyons (2000) says, "Right or wrong, Chomsky's theory of grammar is undoubtedly the most dynamic and influential; and no linguist who whishes to keep abreast of current development in his subject can afford to ignore Chomsky's theoretical pronouncements. Every other 'school' of linguistics at the present time tends to define its position in relation to Chomsky's views on particular issues."

2. Deep structure and surface structure

According to Chomsky, a sentence may have two levels of syntactic representation. Deep structure is the abstract representation of the underlying level of structural relations between its different constituents of a sentence. From this abstract underlying structure, the actual form of a sentence is derived. Deep structure is generated by the base component. Surface structure is a formal representation of the final syntactic form of a sentence, as it exists after the transformational component has modified a deep structure. It is derived from the Deep Structure.

A deep structure may have different surface structures:

a. The man opened the door.

b. The man didn't open the door.

c. Did the man open the door?

d. Didn't the man open the door?

$e$. The door was opened by the man.

$f$. The door was not opened by the man.

g. Was the door opened by the man?

$h$. Wasn't the door opened by the man?

A surface structure may come from different deep structures.

Eg. He is anxious/difficult to teach.

Flying planes can be dangerous.

(If you fly planes you are engaged in a dangerous activity; planes that are flying are dangerous objects)

Deep structure is more intimately connected with sentence meaning than surface structure is. Surface structure, on the other hand, is more intimately connected with the way the sentence is pronounced. The deep structure of a sentence is the out of the base component and the input to both the transformational component and the semantic component; the surface structure of a sentence is the output of the transformational component and the input to the phonological component. Later, in his extended standard theory, Chomsky (1965) points out that not only deep structure but also surface structure has a close relationship with semantic representation. All the sentences are composed of deep structure and surface structure. The later is transformed from the former. Look at the following examples.

(3) I persuaded John to leave.

(4) I expected John to leave.

(3a) I - persuaded-a specialist-a specialist will examine John.

(3b) I - persuaded-John-a specialist will examine John.

(4a) I- expected-a specialist will examine John.

(4b) I - expected-John-to be examined by a specialist.

Thus, (3a) is different from (3b), while (4a) is the same as (4b).So, (3) and (4) have the same surface structure but different deep structures.

The integrated generative grammar includes three parts-syntactic structures, phonologic structures and semantic structures. Every SD (syntactic description) has a deep structure and a surface structure. Semantic structures give a semantic explanation to the deep structure and phonologic structure endows a phonologic manifestation with the surface structure.

Generally, ambiguous sentence has just one surface structure, but several deep structures. For example: 
(5)The police were ordered to stop drinking after midnight.

a. The Police-were ordered-the police stop drinking after midnight.

b. The Police-were ordered-the police stop the people from drinking after midnight.

c. After midnight-the police-were ordered-the police stop drinking.

d. After midnight-the police-were ordered-the police stop the people from drinking.

(6)I don't steal from John because I like him.

a. (I steal from John) because I like him.

b. (I steal from John (because I like him)).

3. X-bar theory

$\mathrm{X}$-bar Theory is a theory about phrasal structure, revealing the structural properties of syntactic representations. It deals with not only phrases, but clauses and sentences as well.

According to X-bar theory, all phrasal structures (including phrases, clauses and sentences in the traditional sense) are endocentric and all can be represented by the X-bar schema. X-bar theory holds that all phrasal structures are projected by the head, hence are known as maximal projection, while the head is zero projection. There also can be intermediate projections between maximal projection and the head. So phrases can be represented as follows:

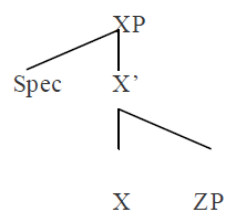

Through further studies, we find that infinitive sentences can be viewed as the maximal projection of the inflection (I or INFL for short), and a complementizer sentence the maximal projection of the complementizer. That is to say, sentences, treated as exocentric in traditional grammar, are also endocentric. They also satisfy the X-bar schema.

According to X-bar theory, head X can either be a lexical category or a functional category. It enables a tree diagram to reflect at least two syntactic dimensions: content and function. The structure of a sentence consists of both lexical phrases and functional phrases, each of them sharing the same skeleton:

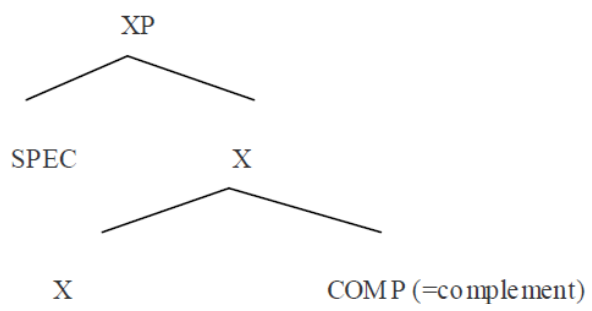

And this skeleton is universal. We can use it to analyze any sentence in any language. In other words, all constituents of a sentence in any language can find its own position in an X-bar tree diagram.

According to the above diagram, X-bar strives for the maximum generality. It makes statements about phrase structure true for all phrases rather than for one rule or one phrase type. Thus it expresses cross-category generalizations about the need for a head, a particular type of head, and for an intermediate level with the phrase, independently of whether the phrase is NP, VP, or any other type of phrase. It relies on two main structure relationships within the phrase: one is the link between the head and the complement sisters; the other is between the specifier and the head. In English, almost all heads come before complements. Three examples are taken for illustration.

(3) The man smokes a cigarette.

(3)'

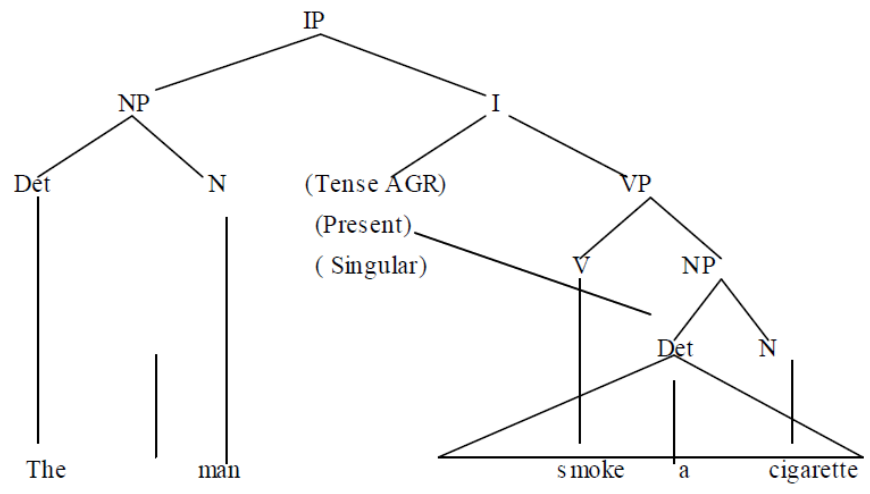


Derived from the above structure's analysis, Chomsky's X-bar theory about both the lexical phrases and functional category are clearly shown in the above graph.

Once a sentence is ambiguous, it must have two or more different phrasal hierarchical structures in the structure graphs analyzed by X-bar theory. Another example is taken to show where the ambiguity takes place:

(6) He gives me a hot evening drink.

(6)'a

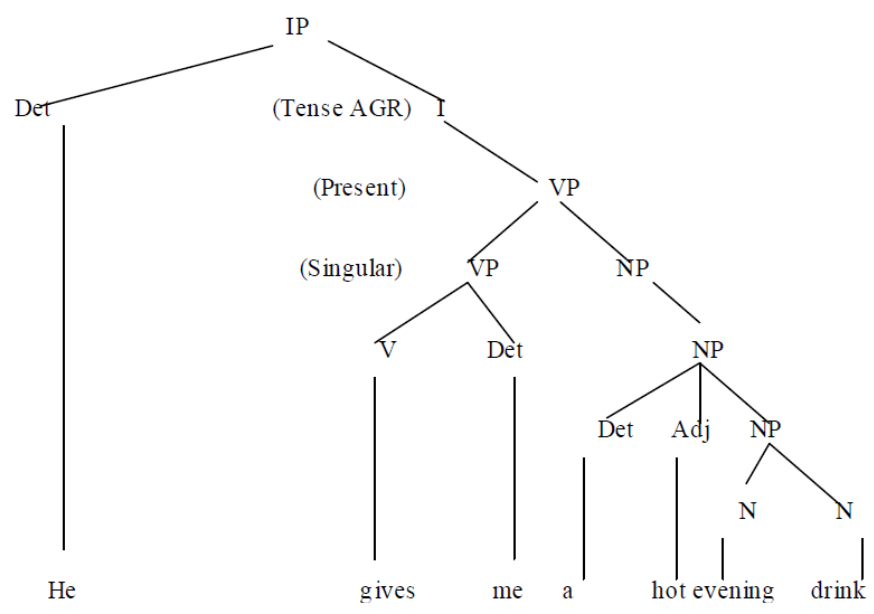

b.

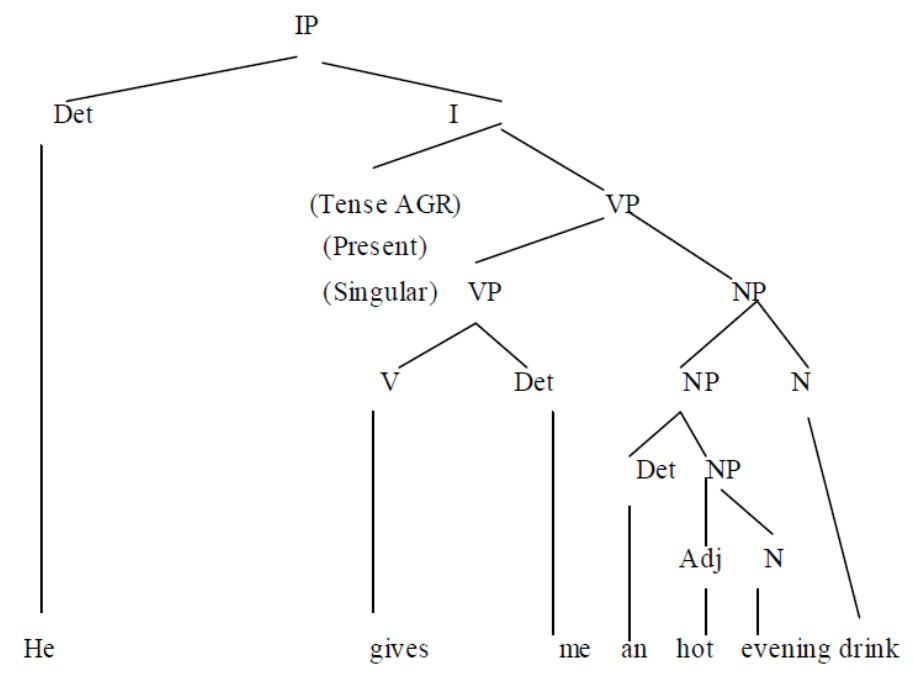

For example (6), in NP (a hot evening drink), whether Adj (hot) is related to N (evening) or N (drink) leads to ambiguity. The S-structure of the NP (a hot evening drink) indicates the Adj (hot) has two hierarchical positions: one is the sister of NP in (6)'a and the other is the sister of N in (6)'b. It is the Adj's two hierarchical positions suggested by the NP' S-structure that produces ambiguity. The ambiguity is caused by Adi so it is called AdjP ambiguity.

It is concluded that, by X-bar theory and Structure-dependency, where an ambiguity occurs is in a phrase, and in S-structure the unit that suggests more than one hierarchical position in D-structure is a phrase. Hence ambiguity can be categorized into NP ambiguity, VP ambiguity (including non-finite verb) PP ambiguity Adj ambiguity, Adv ambiguity and clause ambiguity.

\section{CONCLUSION}

From the above comparison, it can be safely drawn that sentence component analysis (also called traditional grammar analysis) is widely used in ambiguity teaching to prove the presence of ambiguity in a forceful way, however, teachers have to previously resort to tuitions and traditional grammar to foretell ambiguity before analyzing it. In addition to that, the analysis is superficial in a linear order. IC analysis not only proves the existence of ambiguity, but indicates the possibility of ambiguity and the number of the D-structures to which an S-structure can be traced back. IC analysis is thus more effective than sentence component analysis. But neither of them can tell the reason why ambiguity is turned out, what the generative mechanism of ambiguity is and how ambiguity is generated. Chomskyan TG grammar deeply discovers the cause and generative mechanism of ambiguity's appearance through the movement from D-structure to 
S-structure besides telling the presence and number of ambiguity.

\section{REFERENCES}

[1] Adger, D. (2003). Core Syntax: A Minimalist Approach. Oxford: Oxford University Press.

[2] Chomsky, N. (1965). Aspects of the theory of syntax. Cambridge, Massachusetts: MIT Press,

[3] Herndon, J.H. (1976). Survey of Modern Grammars. New York: Harcourt College Publishers.

[4] Kaplan, A. (1989). An Experimental Study of an Ambiguity and Context. New York: New York Press.

[5] Kilby and Roca. (1982). Foundations of General Linguistics. London: Unwin Hyman.

[6] Lyons, J. (2000). Linguistic Semantics: An Introduction. Cambridge: Cambridge University Press.

[7] Ouhalla, J. (2001). Introducing Transformational Grammar: From Principles and Parameters to Minimalism. Beijing: Foreign Language Teaching and Research.

[8] Radford, A. (1981). Transformational Syntax: A Student's Guide to Chomsky's Extended Standard Theory. Cambridge: Cambridge University Press.

[9] Radford, A. (1997). Syntactic Theory and the Structure of English: A Minimalist Approach. Cambridge: Cambridge University Press.

[10] Eugene O. Winter. (1977). "A clause-relational approach to English texts: A study of some predictive lexical items in written discourse", Instructional Science. http://link.springer.com/article/10.1007\%2FBF00125597 (accessed 29/2/3013).

Fangfang Ding was born in Chongqing, China in 1980. She received her MA degree in English linguistics from the Southwest University in 2009.

She is currently a lecturer in Sichuan Agricultural University Sichuan, China. Her research interests include cognitive linguistics and second language acquisition. 